\title{
Research on control algorithm of high voltage circuit breaker three phase permanent magnet brushless DC motor
}

\author{
Fucheng Lang \\ Electric Power Research Institute of State Grid Liaoning Electric Power Co. , Ltd., Shenyang, Liaoning, \\ 110006, China
}

High Voltage and Large Current Laboratory of State Grid Corporation, Shenyang, Liaoning, 110006, China

Hongkui Zhang

CCTEG Shenyang Research Institute, Fushun, Liaoning, 113122, China

\begin{abstract}
Aiming at the high voltage circuit breaker three-phase permanent magnet brushless DC motor, this paper studies the motion characteristics of the motor operating mechanism under different control strategies. Considering the switching operation process of high voltage circuit breaker, we established the permanent magnet brushless DC motor operating mechanism motion simulation model of the control system. It was controlled by the digital double closed loop and the inner is current loop, where a PI controller is adopted. The outer ring is speed ring, which was controlled by two different control strategies, the traditional PID controller and single neuron PID controller. Through the simulation analysis of servo control system, the tracking control performance of the motor operating mechanism is obtained. The results show that the single neuron PID controller can achieve better tracking control of the contact speed, making it moving by the ideal motion characteristic curve. It is an ideal and effective control method.
\end{abstract}

KEYWORD: high voltage circuit breaker; brushless DC motor; traditional PID controller; single neuron PID controller

\section{INTRODUCTION}

In power system, the breaker interrupting capacity has great difference due to the high voltage circuit breaker has different actual circuit parameters under different working state of the power system (such as no-load, load and short circuit fault). Different voltage level circuit breakers have different opening and closing characteristics in the same working condition. Traditional high voltage circuit breaker operating mechanism adopts spring, hydraulic or pneumatic technology, which has many connecting rods and complicated structure, the cumulative movement tolerance is large and the response is slow. It is difficult to achieve reliable control of the contact movement.

The circuit breaker stroke is very short and opening and closing time is only a few tens of ms. The speediness and controllability of operating mechanism are directly related to whether the contact can be acted by the predetermined speed curve and the interrupting capacity and reliability of breaker. The permanent magnet brushless DC motor operating mechanism connected the motor spindle with the operating rod, which can directly drive circuit breaker main shaft moving and remove the complex transmission mechanism. It has little movement parts and small movement dispersion. The development of power electronics technology and modern control theory has realized the precise control of motor speed, which provides the possibility for the reliable control of the high voltage circuit breaker brushless DC motor operating mechanism.

\section{PERMANENT MAGNET BRUSHLESS DC MOTOR}

\subsection{Overall structure}

This paper aims at $40.5 \mathrm{kV}$ vacuum circuit breaker developed a permanent magnet brushless DC motor operating mechanism, as shown in Figure 1. The motor operating mechanism and insulating pull rod in arc extinguish chamber are connected by a set of a four bar linkage mechanism, which composed by a rotating shaft, a crank arm, a spring contact, insulating pull rod and a triangular turn arm. The operating mechanism of the motor is driven by the four connecting rod mechanism to drive the insulating pull rod to realize the opening and closing operation of the circuit breaker. 


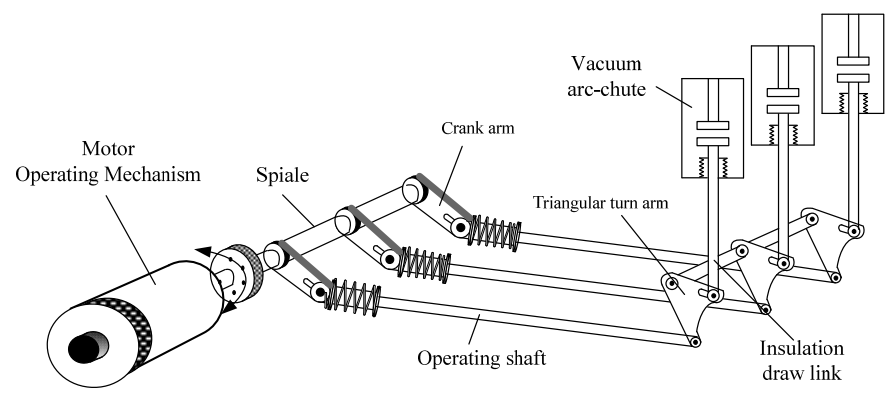

Fig 1 structure drawing of permanent magnet brushless DC motor operating mechanism

\subsection{Mathematical model}

The overall structure of the permanent magnet brushless DC motor of high voltage circuit breaker is shown in Figure 2, which is mainly composed of a permanent magnet brushless DC motor, a limit device and a photoelectric encoder. The driving motion of high voltage circuit breaker is generated by the motor body and it can achieve the hold function by using the limit device in opening and closing position. Meanwhile, photoelectric encoder is adopted to detect the rotor position and provide position feedback for servo system to realize the precise control of motor motion process.

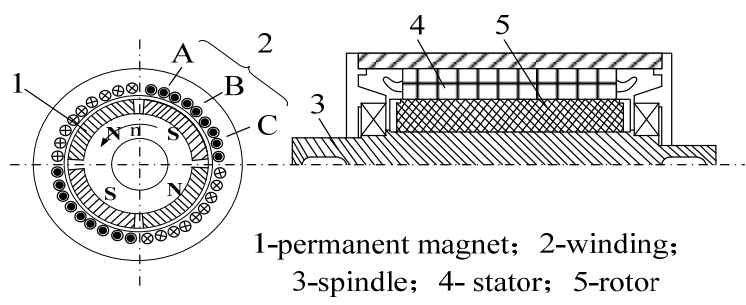

Fig 2 structure drawing of permanent magnet brushless DC motor

In order to highlight the main problems in the analysis of the dynamic mathematical model of the brushless DC motor, we do the following assumptions: (1) the stator winding is $60^{\circ}$ phase with full pitch concentrated winding, Y-type connection; (2) neglect of magnetic saturation, regardless of hysteresis and eddy current losses; (3) rotor without damping winding, permanent magnet not forms the damping effect; (4) without considering the armature reaction, the air gap magnetic field distribution is a trapezoidal wave, wide flat top is $120^{\circ}$ electrical degrees.

(1) Torque equation

$\theta_{\mathrm{p}}$ is coordinates position at a certain point on air gap circumference, $\theta$ is rotor angular displacement with respect to the original position. The magnetic induction intensity of rotor in the air gap circumference $\theta_{\mathrm{p}}$ is:

$B_{r}\left(\theta_{p}, \theta\right)=B_{m} f\left(\theta_{p}-\theta\right)$
In the above equation, $\mathrm{Bm}$ is magnetic flux density amplitude; $f(\theta)$ is the distribution function of rotor flux density, which form is determined by the structure of the motor and its value is merely influenced by stator and rotor relative position $(\theta p-$ $\theta$ ). At the same time, it is obvious that $\mathrm{f}$ is a periodic function due to the symmetry structure of the motor. According to the structure of the motor, the magnetic induction intensity generated by rotor on circumference air gap of each phase winding can be obtained. Thus, the electromagnetic force of conductors is as follows:

$\left\{\begin{array}{l}T_{a}=2 n r B_{a} l i_{a}=l i_{a} B_{m} f(\theta) \\ T_{b}=2 n r B_{b} l i_{b}=l i_{b} B_{m} f\left(\theta+60^{\circ}\right) \\ T_{c}=2 n r B_{c} l i_{c}=l i_{c} B_{m} f\left(\theta+120^{\circ}\right)\end{array}\right.$

In the above equation, $T a, T b, T c$ is electromagnetic torque of each phase winding, $i a, i b$, $i c$ is current in the conductor, $l$ is the effective length of conductor.

(2) Electric potential balance equation

The counter electromotive force of each phase winding is shown as followings:

$\left\{\begin{array}{l}e_{a}=B_{a} l v=\operatorname{lr} \omega B_{m} f(\theta) \\ e_{b}=B_{b} l v=\operatorname{lr} \omega B_{m} f\left(\theta+60^{\circ}\right) \\ e_{c}=B_{c} l v=\operatorname{lr} \omega B_{m} f\left(\theta+120^{\circ}\right)\end{array}\right.$

In the above equation, $\mathrm{r}$ is the effective radius of motor rotor; $\mathrm{w}$ is angular velocity of rotor. The electric potential balance equation is shown as followings.

$\left[\begin{array}{l}u_{a} \\ u_{b} \\ u_{c}\end{array}\right]=\left[\begin{array}{ccc}L & M & M \\ M & L & M \\ M & M & L\end{array}\right] P\left[\begin{array}{l}i_{a} \\ i_{b} \\ i_{c}\end{array}\right]+\left[\begin{array}{lll}r & 0 & 0 \\ 0 & r & 0 \\ 0 & 0 & r\end{array}\right]\left[\begin{array}{l}i_{a} \\ i_{b} \\ i_{c}\end{array}\right]+\left[\begin{array}{l}e_{a} \\ e_{b} \\ e_{c}\end{array}\right]$

In the above equation, $L$ is the self inductance of each phase winding $(\mathrm{H}) ; M$ is the mutual inductance between the two phases; $P$ is differential operator $\mathrm{P}$ $=\mathrm{d} / \mathrm{dt}$.

(3) Motor kinematic equation

Motor kinematic equations satisfy the following equation:

$\left\{\begin{array}{l}T_{e m}-T_{l}=J \frac{d \omega}{d t} \\ \omega=\frac{d \theta}{d t}\end{array}\right.$

In the above equation, Tem is electromagnetic torque; T1 is load torque; $\mathrm{J}$ is rotational inertia of rotor; $\theta$ is revolving angels of motor

\section{CONTROL STRATEGY AND METHOD RESEARCH}

The opening and closing operation movement of high voltage circuit breaker is a process of short time, large inertia, nonlinear and variable load. Aiming at motor operating mechanism control strategy analysis and based on the traditional PID 
control theory, the intelligent control theory is introduced in this paper.

\subsection{Speed characteristics of the motor under the control of traditional PID}

In digital double closed loop of the high voltage circuit breaker moving contact movement control, the speed adjustment uses the incremental PID control algorithm to obtain the best dynamic effect. The output speed is the reference value of the current, and the calculation formula is as follows:

$I_{\text {ref }}(k)=I_{\text {ref }}(k-1)+\left(K_{\mathrm{PI}}+K_{\mathrm{II}} T_{\mathrm{I}}+K_{\mathrm{DI}} / T_{\mathrm{V}}\right) e(k)$

$-\left(K_{\mathrm{PI}}+2 K_{\mathrm{DI}} / T_{\mathrm{v}}\right) * e(k-1)+K_{\mathrm{DI}} e(k-2) / T_{\mathrm{v}}$

In the above equation, $\operatorname{Iref}(k)$ is speed adjustment output and the current adjustment reference value; $K_{P I}$ is velocity ratio coefficient; $K_{I I}$ is velocity integral coefficient; $K_{D I}$ is differential coefficient of velocity; $\quad T_{V}$ is sampling period of speed; $e(k)$ is rate deviation for the $\mathrm{K}$ times.

The regulation of current is a new process of PWM production. The average value of current can be adjusted by adjusting the width of the PWM waveform, and the width of the PWM waveform is achieved by adjusting DSP event manager and the comparison value of the COMP event manager. Its algorithm formula is as follows:

$\operatorname{COMP}(k)=\operatorname{COMP}(k-1)+K_{\mathrm{PV}}[e(k)-e(k-1)]$

$+S K_{\mathrm{IV}} T_{\mathrm{I}} e(k)$

In the above equation, $\operatorname{COMP}(k)$ is current adjustment output; $e(k)$ is current deviation; $K_{P V}$ is current ratio coefficient; $K_{I V}$ current integral coefficient; $S$ is integral separation switch, if $\mid \mathrm{e}(\mathrm{k})$ $\mid<\xi, \mathrm{S}=1$. If $|\mathrm{e}(\mathrm{k})| \geqq \xi, \mathrm{S}=0 ; T_{1}$ is current regulation period

Aiming at the opening and closing process of high voltage circuit breaker, the modeling of the brushless DC motor actuator control system was established. The system simulation model is shown in Figure 3.

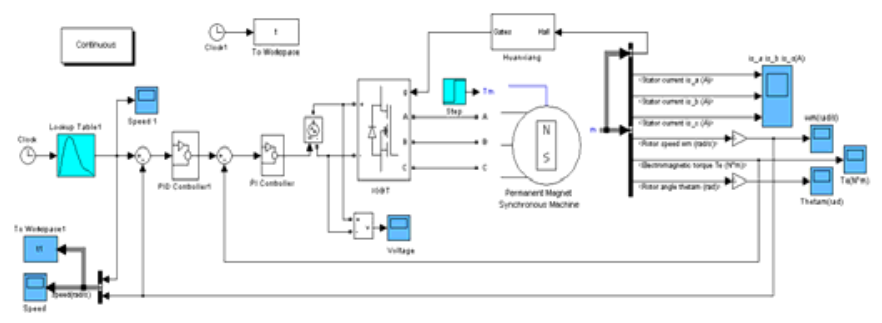

Fig3 Simulation module of control system using routine PID controller

The simulation results are shown in figure 4 . From the results, we can see that system at later period has a big deviation. The traditional PID controller in original system is replaced by single neuron adaptive PID controller and fuzzy adaptive PID controller and other intelligent controllers in outer loop speed regulating device of the system. The hope is that through the further improvement of the control algorithm to improve the effectiveness of the tracking.

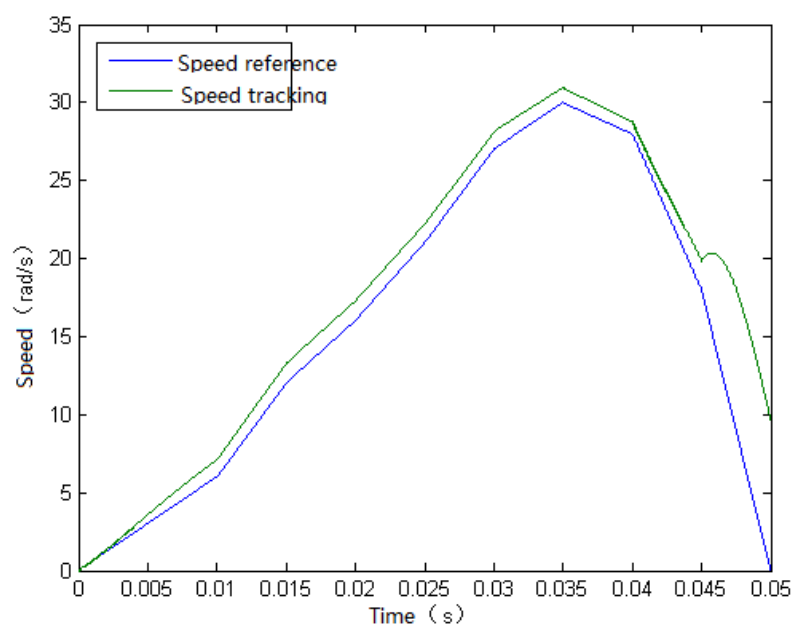

(a) Closing process

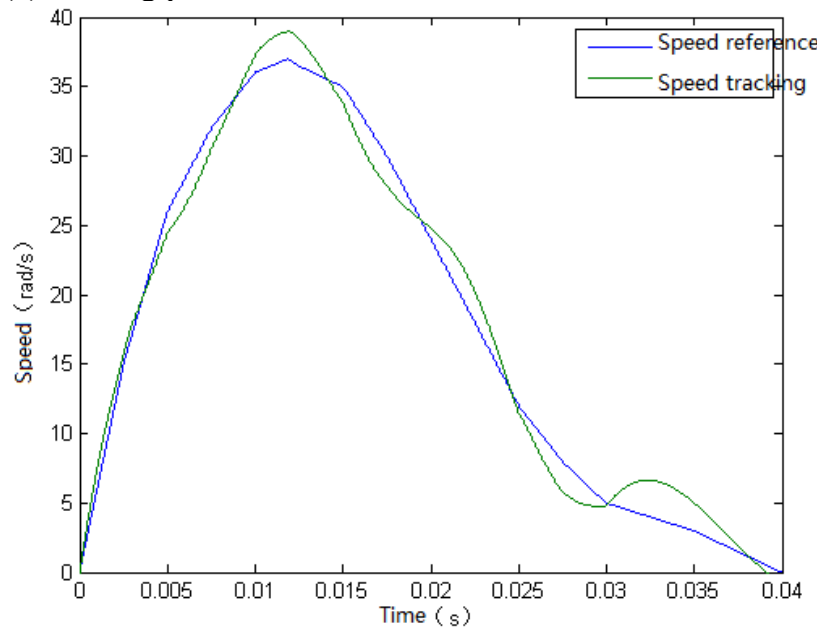

(b) Operating process

Fig4 Simulation curve of speed tracking control using routine PID controller

\subsection{Temperature Rise}

Single neuron adaptive controller achieves the adaptive function by adjusting the regulator weights of proportion, integral, differential. The adjustment of the weight coefficient is based on supervised Hebb learning rule.

Neurons have 3 input variables xi $(\mathrm{k})(\mathrm{i}=1,2,3)$, the input of the converter reflects the deviation state of desired output and the controlled given. If setting given is $\mathrm{yr}(\mathrm{k})$, output is $\mathrm{y}(\mathrm{k})$, deviation is e $(\mathrm{k})$, and $\mathrm{X} 1, \mathrm{X} 2, \mathrm{X} 3$ is the required state after the converter into neuron learning control, where $\mathrm{x} 1=\mathrm{e}(\mathrm{k}), \mathrm{x} 2(\mathrm{k})$ $=\Delta \mathrm{e}(\mathrm{k}), \mathrm{X} 3(\mathrm{k})=\mathrm{e}(\mathrm{k})-2 \mathrm{e}(\mathrm{k}-1)+\mathrm{e}(\mathrm{k}-2), \mathrm{Z}(\mathrm{k})=\mathrm{e}$ (k). They are performance indexes. Neurons produce control signal by an associative search, namely the output signal $\mathrm{u}(\mathrm{k})$ of adaptive neuron is:

$u(k)=u(k-1)+K \sum_{i=1}^{3} w_{i}(k) x_{i}(k)$ 
Among it: wi(k) is the corresponding weights coefficient of $x i(k), K$ is proportionality coefficient of neurons, $\mathrm{K}>0$.

$\frac{\partial y(k+1)}{\partial u(k)}$ is usually unknown in PID control algorithm,

$\operatorname{sgn} \partial y((k+1) / \partial u(k))$ is used instead. The resulting imprecise effects can be compensated by adjusting the learning rate $\eta \mathrm{i}$. After the normalization of the above algorithm, the learning algorithm is as follows:

$$
\left\{\begin{array}{l}
u(k)=u(k-1)+K \sum_{i=1}^{3} w_{i}^{\prime}(k) x_{i}(k) \\
w_{i}^{\prime}(k)=\frac{w_{i}(k)}{\sum_{i=1}^{3}\left|w_{i}(k)\right|},(i=1,2,3) \\
w_{1}(k+1)=w_{1}(k)+\eta_{i} K z(k+1) x_{1}(k) \operatorname{sgn}\left(\frac{\partial y(k+1)}{\partial u(k)}\right) \\
w_{2}(k+1)=w_{2}(k)+\eta_{P} K z(k+1) x_{2}(k) \operatorname{sgn}\left(\frac{\partial y(k+1)}{\partial u(k)}\right) \\
w_{3}(k+1)=w_{3}(k)+\eta_{D} K z(k+1) x_{3}(k) \operatorname{sgn}\left(\frac{\partial y(k+1)}{\partial u(k)}\right) \\
\operatorname{sgn}(x)=\left\{\begin{array}{l}
+1, x \geq 0 \\
-1, x<0
\end{array}\right.
\end{array}\right.
$$

Based on the permanent magnet brushless DC motor and the established single neuron controller model, and aiming at the opening and closing process of high voltage circuit breaker, the modeling of contact motion control system was established here. System structure is shown in Figure 5.

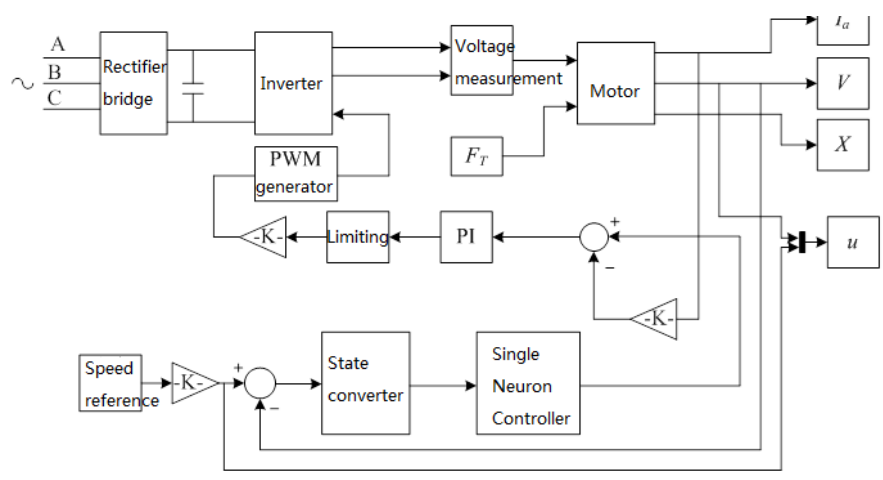

Fig5 The structure chart of of speed tracking system using single-neuron PID controller

\section{SIMULATION ANALYSIS OF HIGH VOLTAGE CIRCUIT BREAKER THREE PHASE MOTOR MECHANISM IN COAL MINE}

\subsection{Simulation of motor mechanism}

The single neuron PID controller is embedded in the contact motion control system to instead of the traditional PID controller in the speed loop. The control system is simulated and the results are shown in Figure 6. From the simulation results, we can see that system speed tracking is improved to some extent, but tracking error is large at high speed. For applications of circuit breaker moving contact movement control, single neuron PID has some disadvantages in terms of stability and accuracy. It should be combined with other control algorithms, such as introducing feed forward controller based on original single neuron PID controller to improve the disadvantages of poor rapidity and big overshoot or other control algorithms.

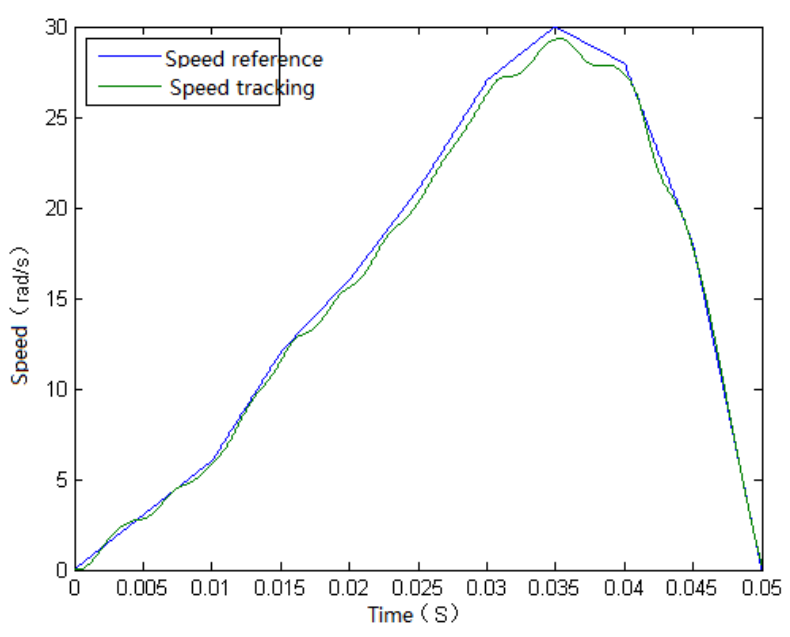

(a) Closing process

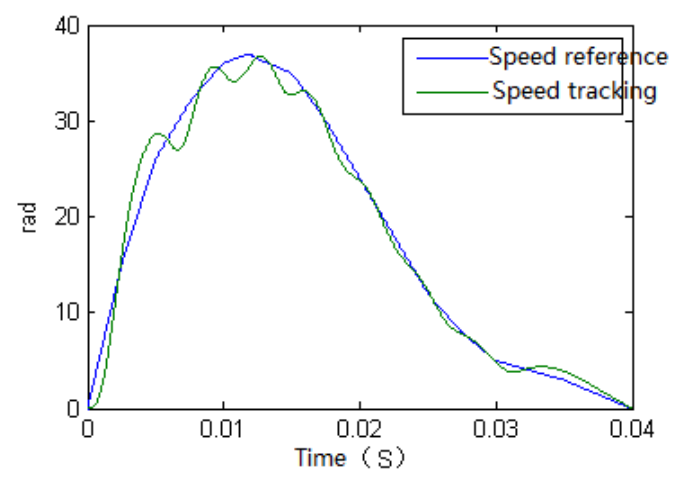

(b) Operating process

Fig6 Simulation curve of speed tracking control using singleneuron PID controller

\subsection{Error analysis}

From above figures, we can see that traditional PID has large error in the process of opening and closing operation, especially in the closing stage, which has maximum error. Single neuron PID tracks better in early period of opening and closing operation and low fluctuations of error curve in the process of opening and closing operation, especially the closing operation velocity tracking curve and the given curves almost coincide. Therefore, the single neuron PID controller has high stability and good tracking performance, and it is an ideal choice for the servo system simulation analysis of the high voltage 
circuit breaker brushless DC motor operating mechanism control system.

\section{CONCLUSION}

By analyzing the simulation results of high voltage circuit breaker motor operation mechanism control system, it proves that the fuzzy adaptive PID controller in the realization of high voltage circuit breaker brushless DC motor operating mechanism velocity tracking simulation has good response characteristic and high tracking accuracy, which is the ideal choice for speed tracking control system. The research results of this paper provide references for the motor operation mechanism movement control and velocity tracking

\section{ACKNOWLEDGEMENTS}

This work is supported by CCTEG Shenyang Research Institute science\& technology innovation fund (2013MS014), (2014QN015).

\section{REFERENCES}

LI Yusheng, HAO Fengnan. Sealed pole and pouring technique of vacuum circuit breaker[J]. Electric Engineering, 2008 (1):61-62.

LI Jianji. Application of solid sealed pole technology invacuum circuit breaker[J]. Popular Utilization of Electricity, 2005 (4):21-22.

ZHANG Hong-tie, JIANG Guan-yu, FENG Xiang-wei. Improvement of a Kind of Solid-Insulation-Embedded Pole Outlet Line Structure[J]. Electrotechnics Electric,, 2014 (12):51-53

ZHOU Lei,PAN Huang.Brief Analysis on Several Principal Solid Insulation Embedded Vacuum Circuit Breakers[J]. East China Electric Power,2010(8):1286-1288.

YANG Wei-yi, XU Zhong.Technical Research and Development of Mine Flameproof High — voltage Vacuum Distribution Unit [J]. Colliery Mechanical \& Electrical Technology, 2008 (2):44-46.

ZHOU Yibo,WAN Siwei,ZENG Xianwen,LI Shunyao, ZHONG Shijie. Cause Analysis of a $220 \mathrm{kV}$ GIS Leakage and Disc Insulator Breakage[J]. Guangdong Electric Power, 2012 (5): 118-121.

YAO Qiang, WANG Yong,LIU Yong.The Application of Impurity Analysis of SF6 for Fault Diagnosis of GIS[J].High Voltage Appratus,2010,46(5):35-38.

ZOU Ji-yan,DUAN Xiong-ying,LUO Yan.Online Monitoring System of Intelligent Vacuum Circuit Breakers[J]. 2010 (11):1-4. 